\title{
Desain Partisipasi Dalam ruang Publik, Ruang komunal Sosial Dalam Kampung Heritage Tawangsari Sebagai Salah Satu Bentuk Aplikasi Unsur Keberlanjutan Sosial
}

\author{
Ghoustanjiwani Adi Putra, ST., MT \\ Mahasiswa Prodi Arsitektur, Fak. Teknik Sipil dan Perencanaan, ITN Malang \\ e-mail: Ghoustanputra@lecturer.itn.ac.id \\ Hani Zulfia Zahro', S.Kom., M.Kom \\ Dosen Prodi Informatika, Fak. Teknik Industri, ITN Malang \\ e-mail: hanizulfia@lecturer.itn.ac.id
}

\begin{abstract}
ABSTRAK
Sosio Culture dari masyarakat Sumbersari sangat tinggi terbukti dengan swadaya bedah Rumah bagi warga kurang mampu dan berberapa kegiatan masyarakat lainya seperti, gotong-royong dan acara kampung Heritage Tawangsari. Tujuan dari peneltian ini adalah melakukan kajian desain partisipasi ruang publik terkait konsep keberlanjutan. Penelitian ini merupakan studi ekplorasi secara kualtitatif dengan mengkaitkan tema terpilih dengan aspek sosial dari konsep keberlanjutan, dimana pada aplikasi desain partisipasi ruang publik di Kampung Tawangsari dinilai salah satu aplikasi konsep berkeanjutan yang memfokuskan dari aspek sosial.
\end{abstract}

\section{Kata kunci : Keberlanjutan, Sosial, Partisipatori,}

\begin{abstract}
Socio Culture from the Sumbersari community is very high, as evidenced renovation House for the poor, and other Social activities such as Neighboorhood Social Gathering and Heritage Tawangsari Festival. The aim of this research is to conduct a study of public space participation design related to the concept of sustainability. This qualitative research based on exporation of case study by linking selected themes to the social aspects of the concept of sustainability, where the application of public space participation design in Tawangsari Village is considered one of the applications of sustainable concepts that focus on social aspects.
\end{abstract}

Keywords : Sustainability, Social, Participatory

PAWON: Jurnal Arsitektur, Nomor 03 Volume III, Juli-Desember 2019, ISSN 2597-7636 


\section{PENDAHULUAN}

Jumlah penduduk di perkotaan menunjukkan kecenderungan pertumbuhan yang semakin meningkat dan cepat. Menjadi sesuatu yang wajar karena daerah perkotaan mempunyai daya tarik yang kuat. Jumlah penduduk perkotaan yang relatif padat tersebut membutuhkan ketersediaan prasarana dan sarana perkotaan dan berbagai fasilitas pelayanan ekonomi juga sosial dalam jumlah yang cukup besar serta kualitas pelayanan umum yang cukup memadai. Sarana prasarana ini termasuk adanya ruang public kreatif sebagai salah satu wadah kegiatan masyarakat. Wadah kegiatan masyarakat yang dapat diwujudkan secara swadaya, salah satunya adalah kegiatan Wisata Sedjarah.Tawang Sari adalah nama lingkungan yang sekarang menjadi wilayah Administratif RW. I Kelurahan Sumbersari Kecamatan Lowokwaru Kota Malang.

Secara administratif, Kelurahan Sumbersari dikelilingi oleh kelurahan lainnya yang ada di Kota Malang. Di sebelah utara, Kelurahan Sumbersari berbatasan langsung dengan Kelurahan Ketawanggede dan Kelurahan Dinoyo, Kecamatan Lowokwaru. Sedangkan di sebelah timur, kelurahan ini berbatasan langsung dengan Kelurahan Oro-oro Dowo dan Kelurahan Penanggungan, Kecamatan Klojen. Di sebelah selatan, Kelurahan Sumbersari berbatasan dengan Kelurahan Gadingkasri, Kecamatan Klojen dan Kelurahan Karangbesuki, Kecamatan Sukun. Lalu, di sebelah barat, Kelurahan ini berbatasan dengan Kelurahan Dinoyo, Kecamatan Lowokwaru dan Kelurahan Karangbesuki, Kecamatan Sukun. (Ngalam.co).

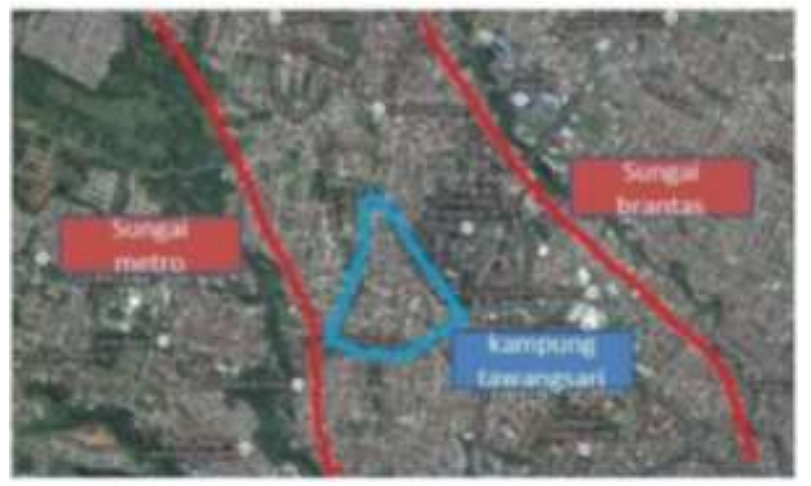

Gambar. 1

Gambar tunggal posisinya pada center text, besarnya supaya diatur Sumber: cantumkan sumber gambar

Sosio Culture dari masyarakat di wilayah ini sangat tinggi terbukti dengan swadaya bedah Rumah bagi warga kurang mampu sukses di gelar secara swadaya oleh warga Sumbersari sendiri. Kesadaran gotong royong juga sangat tinggi salah satunya terbukti dengan partisipasi pemuda dalam Re-

PAWON: Jurnal Arsitektur, Nomor 03 Volume III, Juli-Desember 2019, ISSN 2597-7636 
enactor ngalam yang sudah terbentuk secara swadaya sejak 2007 dan terus berkreasi hingga sekarang dengan belajar sejarah, memahami sejarah dan mencintai sejarah perjuangan. Selain itu ikatan sosial dengan diwujudkanya Kegiatan Kampung Heritage atau kampung sedjarah tawangsari di Sumbersari yang diadakan pada tiap tahun merupakan bukti partisipasi masyarakat sumbersari yang tinggi dan peduli dengan lingkungan mereka. Pada Kelurahan Sumbersari terdapat berbagai potensi diantara nya nilai budaya dan sejarah kampung Sumbersari sendiri yaitu kampung Tawangsari. Dengan Desain Partisipatori yang ditawarkan berupa adanya sosialisasi dan usulan kegiatan kampung Tawangsari sebagai kampung edukasi sejarah kepada masyarakat Sumbersari, kegiatan ini diharapkan mampu menjadi salah satu agenda tahunan kampung Sumbersari Malang.

\section{TINJAUAN PUSTAKA}

\subsection{Desain Partisipatori}

Desain partisipatif adalah sebuah metode desain yang melibatkan pengguna disekitarnya untuk ikut terlibat dalam proses desain. Dimana proses desain partisipatori bertujuan dalam memediasi kebutuhan dan keinginan masyarakat yang disinergikan dengan kepentingan pemerintah, melalui desain partisipatori mampu mewujudkan bentuk desain yang menjadi titik temu dari kedua belah pihak.

Dalam (Ishida,2010): “....Participatory design aims at including users in the design process so that users....". Toru Ishida dalam Introduction to Field Informatics bahwa desain partisipatori merupakan salah satu metode dalam mendapatkan desain users yang tepatguna, pengguna diharapkan mampu berdiskusi dengan stakeholder dan pihak-pihak yang terlibat dalam penyelesaian masalah dan fokus permasalahan. Masih dalam Penelitian Ishida,metode ini dapat digolongkan menjadi 8 tipe klasifikasi yang dapat dikategorikan kedalam:

Dalam proses desain partisipatori diperlukan sebuah proses yang panjang dari dialog antara pemberi kebiajakan (pemerintah), perancang (arsitek, planner) dan masyarakat.

Proses ini dianggap oleh Sanders dalam (Sanders, Elizabeth B-N; SonicRim, 2002) sangat penting karena tujuan dari proses desain partisipatori adalah mencoba memenuhi ekspektasi semua pihak baik pemerintah, masyarakat maupun pihak pihak lain. 
Dalam dunia rancangan, hasil dari kesepakatan yang mufakat mampu menentukan kebutuhan masyarakat yang akan dituangkan dalam produk rancangan yang melalui desain partisipatori tersebut.

Dengan demikian, produk rancangan yang dihasilkan tidak boleh berpihak sebelah artinya produk rancangan yang dihasilkan diharapkan tidak hanya mennghasilkan kebutuhan pemilik dana maupun kekuasaan, melainkan semua lapisan pihak yang terlibat dalam proses tersebut, karena metode desain partisipatif bertujuan mendapatkan mufakat dari kebutuhan produk rancangan yang disesuaikan dengan kepentingan semua pihak yang terlibat (Cowen \& Shenton, 1996).

\subsection{Keberlanjutan Sosial}

Sustainability dapat diartikan sebagai "the continuity of natural environment and natural resources". Sustainability juga berarti suatu pemahaman yang lebih dekat terhadap konsep ekosistem sebelum menghubungkan suatu desain arsitektur dengan lingkungannya, sehingga dapat ditelaah faktor-faktor menuju suatu keadaan lingkungan bumi dan sumber dayanya yang tetap berkelanjutan kualitas daya dukungnya bagi manusia di masa datang (Wiseso, 2000).

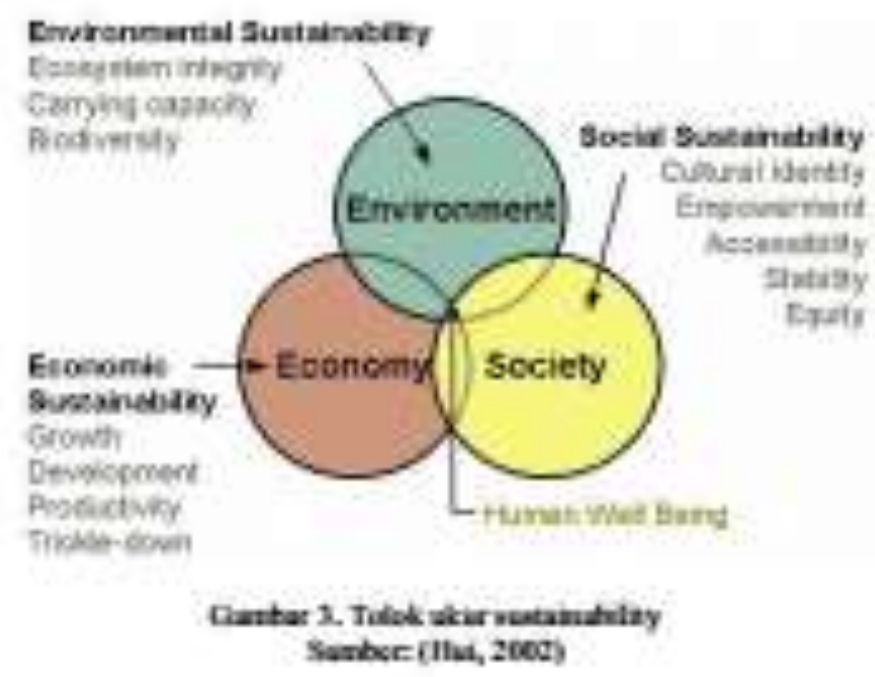

Dalam makalah (Sugeng Triyadi.S, 2008) memaparkan bahwa Ada 3 (tiga) tolok ukur sustainable development, yaitu:

1. Tolok ukur ekonomi (economic sustainability)

2. Tolok ukur lingkungan (environmental sustainability)

3. Tolok ukur sosial (social sustainability) 
Social Sustainability dalam Thin et al (2002) :

- social justice

- solidarity

- participation

- security

Menurut Thin et al Konsep berkelanjutan yang mengedepankan unsur sosial adalah, yang minimal mampu memberikan keadilan yang menyeluruh kesegala lapisan masyarakat, setiap lapisan masyarakat yang terlibat dalam pembangunan tersebut, baik berperan sebagai subjek atau objek, harus mendapatkan perlakuan yang adil dan merata. Konsep keberlanjutan juga diharapkan tetap menjunjung solidaritas yang kuat dengan mempertahankan karakter dari keadaan sosial setempat dan tidak merugikan pihak di dalam sosial tersebut, karena aspek sosial ini menyangkut solidaritas masyarakat yang tinggi. Namun, akan lebih baik lagi apabila pembangunan tersebut justru meningkatkan kualitas sosial yang telah ada..

Hal ini diperlukan agar tercipta suatu stabilitas sosial sehingga terbentuk sosial budaya yang aman dan kondusif.

"...a quality of societies. It signifies the nature-society relationships, mediated by work, as well as relationships within the society. Social sustainability is given, if work within a society and the related institutional arrangements satisfy an extended set of human needs [and] are shaped in a way that nature and its reproductive capabilities are preserved over a long period of time and the normative claims of social justice, human dignity and participation are fulfilled"

Sedangkan dalam Littig and Griebler (2005: 72) menurut Littig bahwa pendekatan untuk konsep keberlanjutan sosial kini tidak lagi didasarkan pada teori keberlanjutan sosial yang konvensional melainkan pada pemahaman praktis pada lapangan yang sesuai perkembangan sosial masyarkat setempat, bahkan telah memasuki ranah agenda politik kebijakan, dimana melibatkan masyarakat kelas menengah keatas seperti birokrasi, stakeholder setempat dan pihak pihak yang dianggap mampu mengeksploitasi sosial masyarakat yang masih alami. 
Kualitas sebuah sosial masyarakat yang alami dapat diukur dari hubungan masyarakat dengan birokrasi setempat, dimana unsur sosial masyrakat marginal dapat dimediasi oleh stakeholder dan planner. Keberlanjutan sosial akan dicapai, jika satu perencanaan dalam suatu kultur masyarakat dan pengaturan institusional maupun stakeholder terkait dapat terpenuhi dan tidak saling merugikan, adanya tuntutan normatif sosial yang terpenuhi, terciptanya keadilan sosial, martabat manusia yang meningkat dan partisipasi sosial yang terpenuhi".

\section{METODE PENELITIAN}

Metodologi secara umum didefinisikan sebagai "a body of methods and rules followed in science or discipline". Sedangkan metode sendiri adalah "a regular systematic plan for or way of doing something". Kata metode berasal dari istilah Yunani methodos (meta+bodos) yang artinya cara.

Metode kualitatif merupakan metode pendekatan penelitian yang digunakan dalam tujuan utama dari penelitian kualitatif adalah intuk didapat sebuah pemahaman mendasar dan mendalam pada lingkup fenomena yang dijadikan fokus tematik penelitian, pendalaman ini meliputi pendekatan secara menyeluruh dengan penggalian pemahaman fenomena lebih dalam (Lexy Moleong, 2000).

Metodologi penelitian ini menggunakan deskriptif eksploratif dari kajian pustaka, dan hasil survei kegiatan kampung tawangsari di Sumbersari Malang.

Dari landasan teori yang dijadikan pijakan kemudian dikembangkan dengan mengeksplorasi keterkaitan dengan isu-isu global yang berkaitan dengan tema penelitian. Studi kasus yang terkait dengan landasan teori dan Isu Global dipilih kemudian dieksplorasi dan dijelaskan secara eksplanatori.

1. Landasan teori: Partisipatori Desain

2. Landasan teori: Sustainable development

3. Isu global: Wacana Sustainability sebagai konsep berkelanjutan pada aspek sosial. 


\section{HASIL DAN PEMBAHASAN}

\subsection{Sosial Kultur Sumbersari}

Sumbersari sebagai Kampung Tawang Sari adalah merupakan salah satu kelurahan dengan angka kepadatan penduduk yang cukup tinggi, selain itu kurangnya ruang terbuka hijau dan ruang komunal warga membuat kawasan kampung ini mendapat imej kampung padat penduduk.

Hampir seluruh rumah milik warga adalah bangunan tinggal dan usaha untuk kos, dan tempat usaha seperti: Warung makan, Laundry, Toko Kelontong, dan usaha yang mendukung usaha kos-kosan.

Sungai kecil yang melintasi Sumbersari adalah sungai disebelah barat wilayah kampung Tawang Sari. Sungai ini sangat tercemar karena jadi pembuangan sampah dan warga banyak membuang limbah keluarga langsung ke sungai ini.

Penduduk Tawang Sari mayoritas memiliki usaha kost dan kuliner. Partisipasi masyarakat di wilayah Tawang Sari sangat tinggi terbukti dengan swadaya bedah Rumah bagi warga kurang mampu sukses di gelar secara swadaya oleh warga Tawang sari sendiri.

Kesadaran gotong royong juga sangat tinggi salah satunya terbukti dengan partisipasi pemuda dalam re-enactor ngalam yang merupakan motor dari Tawang Sari Kampoeng Sedjarah.nKomunitas ini sudah terbentuk secara swadaya sejak 2007 dan terus berkreasi hingga sekarang dengan belajar sejarah, memahami sejarah dan mencintai sejarah perjuangan. 


\subsection{Partisipatori Masyarakat}

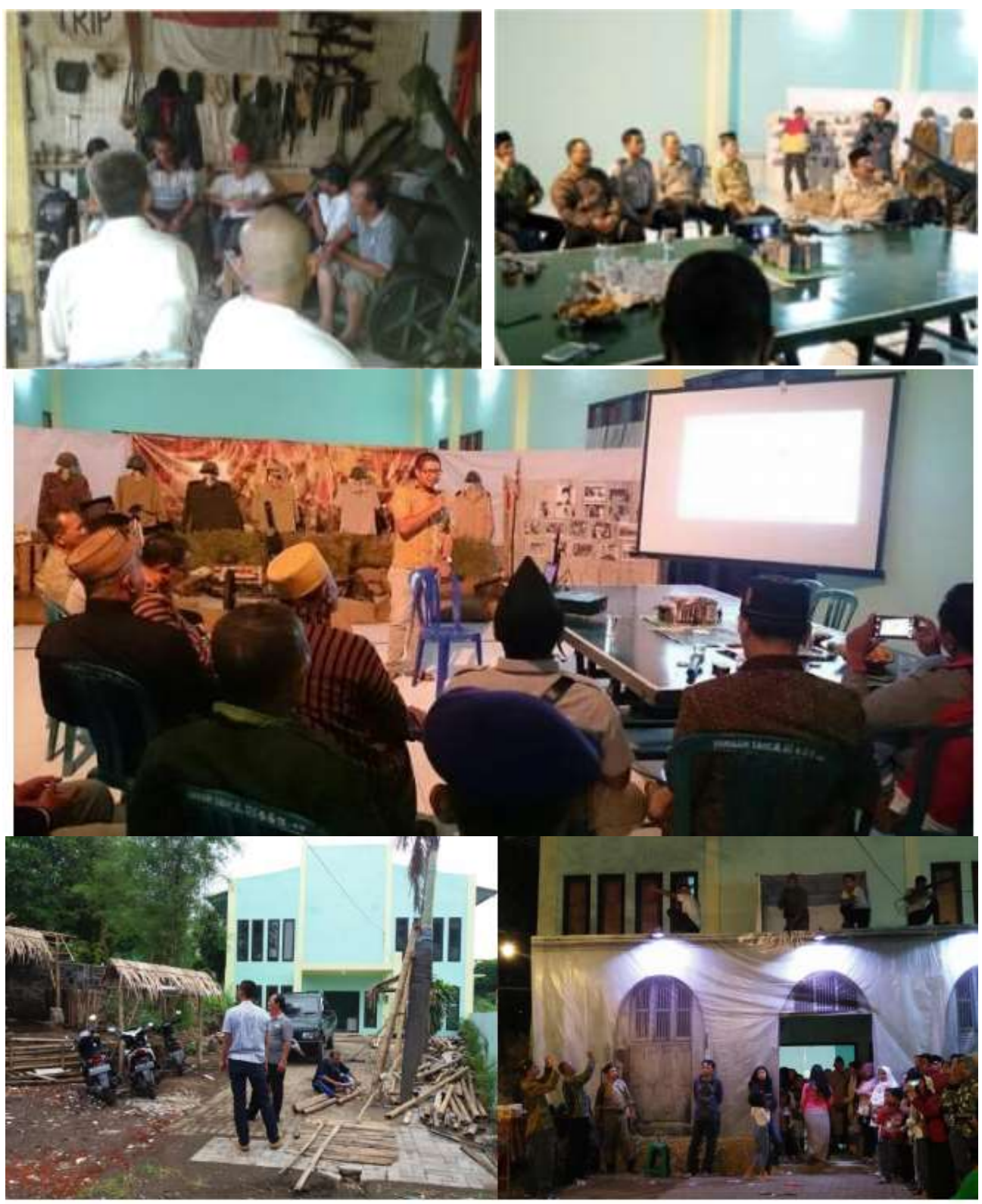

Gambar. 4

Partisipatori Masyarakat Dalam Kegiatan Festival Kampung Sedjarah Sumber: dok. Penulis 
Kekuatan yang di miliki warga Tawang Sari adalah tingkat partisipasi masyarakat yang tinggi dan kekuatan menggalang swadaya masyarakat. Hal ini terbukti dengan program unggulan di RW. I Sumbersari yaitu bedah rumah warga tidak mampu yang dilakukan secara swadaya oleh warga Tawang Sari sendiri. Dengan dukungan dan pemahaman satu visi dan misi seluruh elemen warga kemampuan mewujudkan Kampung tematik di RW. I bisa segera direalisasi dengan diawali pelaksanaan Festival Kampoeng Tawang Sari yang dilaksanakan satu tahun sekali secara swadaya dengan memanfaatkan segala sumber daya dan kemampuan yang dimiliki warga Tawangsari sendiri.

Salah satu wujud besarnya solidaritas dan partisipasi warga Sumbersari adalah pada warga RW 01 Kelurahan Sumbersari dimana bersama Yayasan Manarul Huda, secara gotong royong dan swadaya telah berhasil merenovasi rumah salah satu warganya yaitu Misni yang dapat terkategori keluaraga pra sejahtera.

Secara garis besar, kelembagaan partisipator masyarakat sumbersari dalam pengembangan Kampung tematik Tawang Sari sangat mendukung baik dari stakeholder pemerintahan atau organisasi kemasyarakatan tingkat RT dan RW. Hal ini terlihat dari berbagai jenis kegiatan sosial yang berbasis swadana masyarakat yang selalu berhasil direncanakan dan dilaksanakan. Namun Secara kelembagaan masyarakat sumbersari perlu dilakukan pembinaan dan pendampingan dari stakeholder terkait untuk pengembangan lebih lanjut agar ide-ide masyarakat tersebut bisa terealisasi.

Desain Partisipatori dapat dikatakan sebagai desain yang dikerjakan secara bersama-sama yang dapat dijadikan salah satu alternatif metode dalam merancang produk arsitektur yang berwasawan lingkungan dan sosial yang memiliki kondisi obyek perancangan dengan kultur sosial yang beragam.

Rancangan Pengembangan Kampung Tematik yang diusulkan oleh warga Sumbersari untuk Lomba rancang Malang membutuhkan waktu dan proses yang cukup panjang jika proses tersebut baik melalui proses pengerjaan fisik maupun non fisik, hal ini dikarenakan adanya keterbatasan dana untuk mendukung kegiatan dan perencanaan yang dikehendaki bersama. Disini ada 2 Jenis Rancangan, yaitu Rancangan yang linier satu tema dengan tema heritage "Tawang Sari Kampoeng Sedjarah" dan Rancangan Pendukung dan Penunjang yang merupakan rencana induk dari pengembangan Kampung Tawangsari Sumbersari. 


\subsection{Keberlanjutan Sosial}

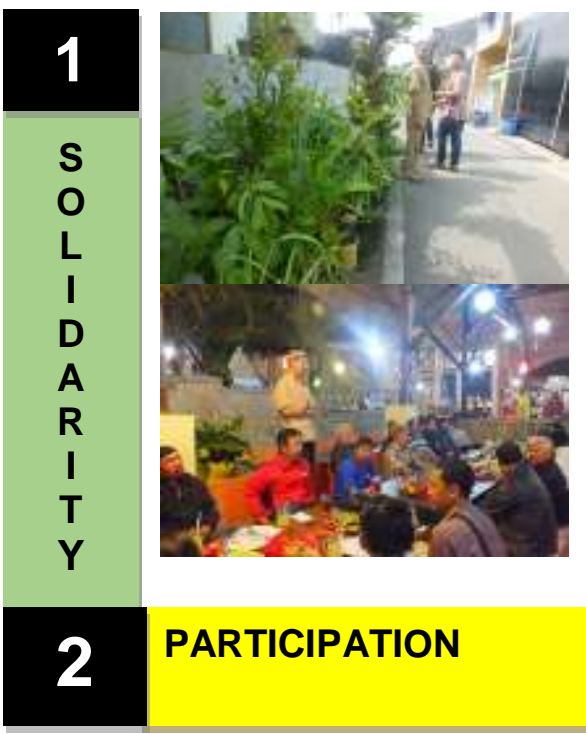

Partisipaasi warga sumbersari dari kegiatan FGD kampung Tematik memiliki antusias yang tinggi. Melalui membinaan dan pendampingan dalam merencanakan Kampung Sedjarah. Warga Sumbersari bekerja bersama untuk mewujudkan Tawangsari Kampung Sedjarah melalui proses FGD dan Desain Partisipatori yang terus berlanjut

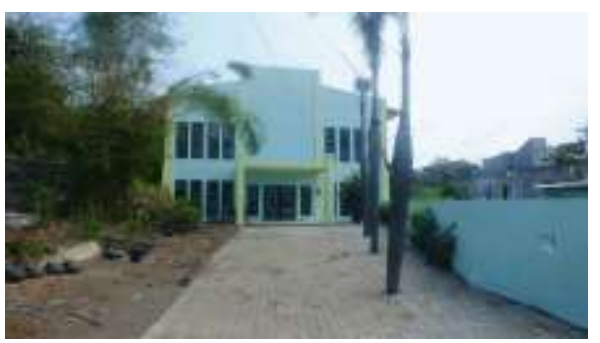

Balai RW sebagai tempat komunal warga yang mampu memberikan keamanan bagi warga sumbersari dan sebagai salah satu ruang penampung aspirasi warga Sumbersari. Balai RW menjadi salah satu media komunikasi dan "rembug" warga untuk menjaga lingkungan yang harmonis sehingga tercapainya kesejahteraan bersama.
Solidaritas warga sumbersari sangat tinggi hal ini di dukung dari berbagai kegiatan sosial masyarakat yang harmonis seperti: acara kemerdekaan RI, Kumpul warga, Saresehan, Partisipasi dalam kegiatan karnaval tahunan, bedah rumah warga yang membutuhkan dengan biaya swadana, kegiatan balai RW 1 yang tidak pernah sepi, kegiatan karang taruna.

Dari berbagai jenis contoh kegiatan seperti ini menandakan bahwa warga sumbersari memeiliki solidaritas yang sangat tinggi.

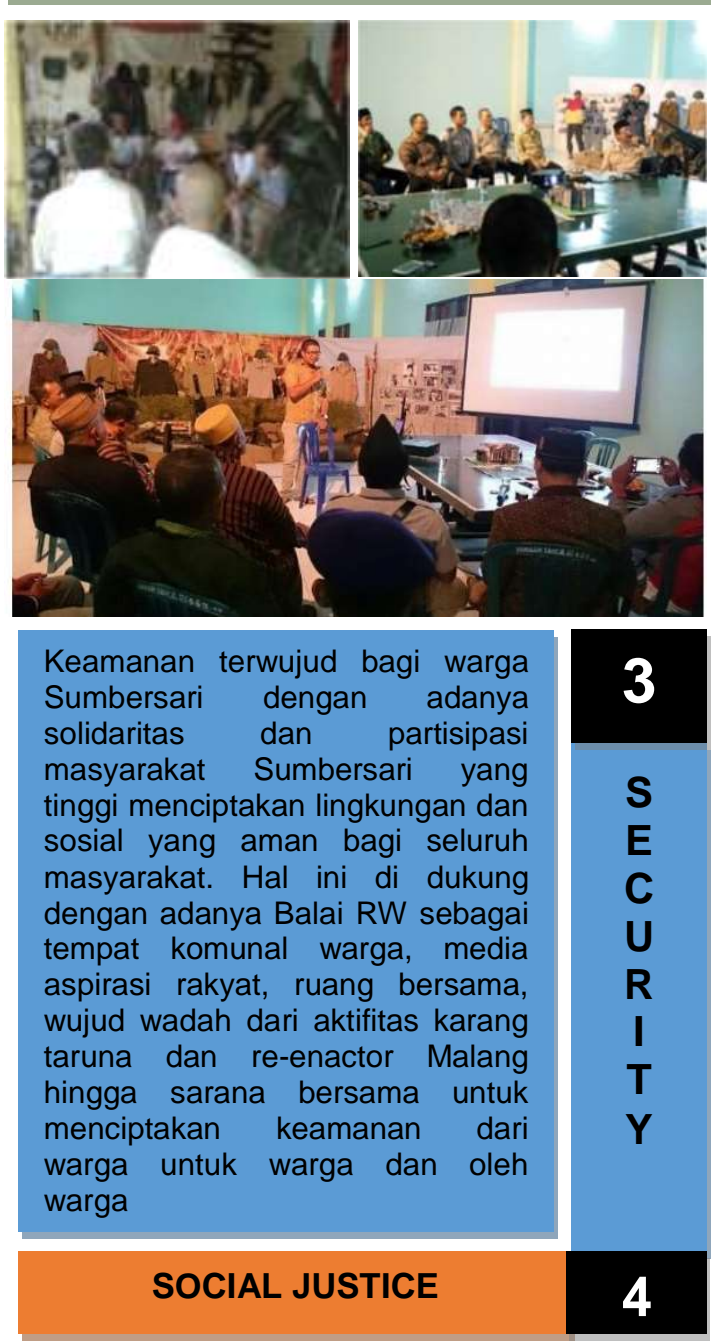

PAWON: Jurnal Arsitektur, Nomor 03 Volume III, Juli-Desember 2019, ISSN 2597-7636 
Keberlanjutan sosial mampu membentuk struktur sosial kemasyarakatan yang baik. Seperti dalam (Hui, 2002), keberlanjutan sosial mewujudkan human wellbeing yang baik.

Keberlanjutan Sosial adalah aspek ketiga yang perlu sangat diperhatikan dalam konsep sustainability, keberlanjutan sosial dapat diwujudkan dengan berberapa kegiatan sosial secara swadaya antara lain:

1. Pengkaderan (melibatkan semua warga) sebagai kader lingkungan secara langsung terlibat dan bertanggung jawab terhadap penjagaan lingkungan mereka, hal ini telah terlihat dalam kegiatan Kampung Tawangsari Sumbersari, dimana hampir seluruh lapisan masyarakat RW 1 tersebut terlibat.

2. Pembentukan manajemen sosial yang terstruktur, Balai RW 1 dengan jajaran perangkat RW berikut Karang Taruna dan Reenactor kota Malang mampu bersinergi dalam kegiatan Kampung Sejarah Tawangsari.

3. Pemberdayaan ekonomi warga sebagai salah satu tujuan utama program community Center untuk mewujudkan sebuah lapangan pekerjaan yang baru bagi warga. Malalui kegiatan Kampung Sejarah Tawangsari di Balai RW 1 masyarakat Sumbersari dapat menambah penghasilan masyarakat sekitar dengan berjualan makanan dan pernak pernik barang Sedjarah.

\section{KESIMPULAN}

1. Kampung Tawangsari Sumbersari dapat dikatakan salah satu kampung dengan kultur sosial dan budaya yang bervarian, hal ini terlihat dari warga sumbersari bukan hanya berasala dari kota Malan sendiri, melainkan pendatang karena hampir seluruh hunian warga difungsikan untuk kos. Kultur sosial budaya Sumbersari pada kampung Sedjarah Tawangsari mampu dipersatukan dengan adanya Balai RW1

2. Keberlanjutan sosial dari Aspek: Solidarity, Participation, Security dan Social Justice merupakan aspek yang harus ada dan melengkapi satu sama lain dalam menciptakan lingkungan sosial yang Berkelanjutan

\section{DAFTAR PUSTAKA}

Hui, S. C. (2002). arch.hku. Retrieved april 01, 2011, from arch.hku:

Littig, B. and Griebler, E., (2005) International . Journal of Sustainable Development, Vol. 8: 1/2, 65-79 
Thiin N, Lockhart C. and G. Yaron (2002), Conceptualising Socially Sustainable Development, DFID, mimeo

Sugeng Triyadi.S, A. H. (2008). Kajian Struktur Dan Konstruksi Bangunan. sustainability-ed. (2010). sustainability-ed. 